\title{
Laboreal
}

Volume $10 \mathrm{~N}^{\circ} 1 \mid 2014$

Análise ergonómica do trabalho e formação

\section{Prólogo e introducción del libro "Didáctica psicológica. Aplicación a la didáctica de la psicología de Jean Piaget"}

Prólogo e introdução do livro "Didáctica psicológica. Aplicação da psicologia de Jean Piaget"

Avant-propos et introduction du livre "Didactique psychologique. Application à la didactique de la psychologie de Jean Piaget "

Prologue and introduction of the book "Psychological didactics. Application of the Jean Piaget psychology"

\section{Hans Aebli}

\section{OpenEdition}

Edición electrónica

URL: http://journals.openedition.org/laboreal/5440

DOI: $10.4000 /$ laboreal. 5440

ISSN: 1646-5237

Editor

Universidade do Porto

Referencia electrónica

Hans Aebli, « Prólogo e introducción del libro "Didáctica psicológica. Aplicación a la didáctica de la psicología de Jean Piaget" », Laboreal [En línea], Volume 10 Nº1 | 2014, Publicado el 01 julio 2014 consultado el 24 septiembre 2020. URL : http://journals.openedition.org/laboreal/5440 ; DOI : https:// doi.org/10.4000/laboreal.5440

Este documento fue generado automáticamente el 24 septiembre 2020

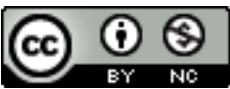

Laboreal está licenciado com uma Licença Creative Commons - Atribuição-NãoComercial 4.0 Internacional. 


\section{Prólogo e introducción del libro "Didáctica psicológica. Aplicación a la didáctica de la psicología de Jean Piaget"}

Prólogo e introdução do livro "Didáctica psicológica. Aplicação da psicologia de Jean Piaget"

Avant-propos et introduction du livre "Didactique psychologique. Application à la didactique de la psychologie de Jean Piaget "

Prologue and introduction of the book "Psychological didactics. Application of the Jean Piaget psychology"

Hans Aebli

\section{REFERENCIA}

Artigo original : Aebli, H. (1951). Didactique psychologique. Application à la didactique de la psychologie de Jean Piaget. Neuchâtel : Delachaux \& Niestlé.

\section{NOTA DEL EDITOR}

http://dx.doi.org/10.15667/laborealx0114haes

\section{Prólogo [']}

1 Por sí solos, los títulos de las obras de Jean Piaget ponen en evidencia la relevancia que su doctrina científica debe revestir para la didáctica. La génesis del número en el niño, El 
desarrollo de las cantidades en el niño, La geometría espontánea en el niño, todos estos títulos dejan entrever un rico material de observaciones y reflexiones que se presta a una aplicación inmediata en la enseñanza : impresión que viene a confirmar el estudio más profundo de esta gran obra psicológica.

2 La psicología de Jean Piaget es genética. No se limita a estudiar las reacciones características del adulto o de un periodo aislado de la infancia, sino que analiza la formación misma de las nociones y operaciones en el transcurso del desarrollo del niño. El resultado de ello no solo es una profunda comprensión de los estadios finales del desarrollo mental, sino también un conocimiento preciso de sus mecanismos de formación. Ahora bien, es evidente que estos últimos son los que revisten más interés para el especialista en didáctica. Puesto que este no tiene otro objetivo que el de provocar, de una manera sistemática y consciente, los procesos de formación intelectual que, por su parte, la psicología genética estudia en la actividad espontánea del niño. Y no debemos poner en duda que el conocimiento exacto de estos procesos es absolutamente necesario cuando nos proponemos provocarlos mediante situaciones de aprendizaje y actividades escolares adecuadas.

3 Asimismo, la psicología de Jean Piaget analiza con un éxito particular las funciones mentales superiores, es decir, las nociones, las operaciones y las representaciones que de manera conjunta constituyen el pensamiento humano. También en este caso, esta psicología responde a una necesidad precisa, puesto que los problemas didácticos más difíciles no conciernen a la adquisición por parte del alumno de hábitos, automatismos o de otros mecanismos primitivos, sino a la formación de nociones, representaciones complejas y operaciones que constituyen sistemas de conjunto (tabla de multiplicar, reglas gramaticales, etc.). Sin embargo, es evidente también que solo una psicología como la de Jean Piaget, que ofrece un análisis preciso de las operaciones mentales y de sus grupos y agrupamientos, puede aportar los conceptos necesarios para la solución de problemas didácticos similares : las doctrinas centradas en funciones elementales como la motricidad, la percepción o la asociación no aclaran las reacciones psíquicas más complejas.

4 Aquí presentamos al lector una didáctica general : estudia los caracteres fundamentales de los procesos formadores y deduce de ellos los principios metodológicos en los que debe apoyarse la enseñanza de todas las materias principales. Aunque demos un gran número de ejemplos concretos, extraídos casi siempre de la enseñanza primaria, no encontraremos en este libro la didáctica completa de ninguna materia de enseñanza. Nos hemos propuesto, por el contrario, definir las nociones fundamentales y el marco general comunes a todas las didácticas especiales. Consideraríamos que esta metodología habría cumplido su cometido si se demuestra que puede servir para ordenar mejor el dominio tan complejo de la didáctica, si las tesis emitidas en las partes psicológica y didáctica incitasen a otros investigadores a realizar nuevos experimentos o si los profesores de primaria que los leyesen recibieran algunas ideas nuevas para su trabajo práctico.

5 Al haber sido nosotros mismos profesores de primaria y secundaria, creemos saber lo que el docente espera de una obra didáctica: además de los principios pedagógicos generales, son los ejemplos concretos que muestran exactamente cómo el autor pretende proceder y todo ello, en situaciones escolares reales, que a menudo solo ofrecen a muchos postulados de la nueva escuela posibilidades muy limitadas de realización. Por estos motivos, hemos puesto en marcha numerosos experimentos 
didácticos destinados a controlar cómo y con qué éxito nuestras propuestas pueden ponerse en práctica en condiciones escolares ordinarias [2]. Además, publicamos en el apartado experimental de esta obra unos protocolos detallados de lecciones que hemos impartido en el marco de estos experimentos. Nos disculpamos si estas descripciones pueden parecer escasas a algunos de nuestros lectores : no se reproducen por completo simplemente para permitir a otros investigadores repetir y comprobar nuestro experimento sino también y, sobre todo, para mostrar a nuestros colegas de la enseñanza cómo concebimos la realización práctica de nuestros principios didácticos.

El propio Jean Piaget nos sugirió redactar este trabajo ; sus comentarios y consejos han resultado de gran ayuda durante su realización. Asimismo, nos ha permitido denominar este libro una aplicación a la didáctica de su psicología. Por tanto, deseamos que Jean Piaget acepte la presente obra no solo como una nueva confirmación del valor de su doctrina psicológica, sino también como un signo de nuestro profundo reconocimiento por la confianza y los ánimos que nos ha transmitido de manera constante.

7 Zúrich, junio de 1951.

8 H. A.

\section{Introducción}

\section{La contribución de la psicología a la solución de los problemas didácticos}

El objetivo de esta obra es estudiar algunas de las aplicaciones posibles de la psicología de Jean Piaget a la didáctica.

10 Comenzaremos por plantear el problema y definir sus términos. ¿Qué es, en efecto, la didáctica? Es una ciencia auxiliar de la pedagogía en la que esta última delega para detallar tareas educativas más generales. ¿Cómo conseguir que el alumno adquiera tal noción, tal operación o técnica de trabajo ? Tales son los problemas que busca resolver el especialista en didáctica, recurriendo a su conocimiento psicológico de los niños y sus procesos de aprendizaje.

11 De este modo, existe una didáctica de la aritmética, de las manualidades, del canto, etc.; pero limitaremos el presente estudio a las adquisiciones intelectuales, refiriéndonos - como no podía ser de otra manera- a los demás aspectos de la vida psíquica, en la medida en que constituyen condiciones o consecuencias de la formación intelectual.

12 Con el fin de precisar la contribución que la psicología puede aportar a la solución de los problemas didácticos, comencemos por preguntarnos cómo se establecen generalmente "las tareas de la didáctica". En casi todos los programas escolares, las definimos en términos de nociones que se deben adquirir : nociones de geometría, de física, de aritmética, etc. Estas son "las asignaturas que el alumno debe aprender", que debe asimilar para "conocerlas". ¿Pero qué significa conocer un objeto como "la palanca" o una noción como "la fracción ordinaria" ? ¿Es la capacidad de dar una definición ? Evidentemente, no. ¿Diríamos que el alumno debe poder hacerse una idea de la palanca, imaginar el mecanismo de su funcionamiento ? Puede ser; pero hay que aclarar lo que entendemos exactamente cuando decimos que el niño debe adquirir tal o cual representación. En el campo del pensamiento matemático, el problema es el 
mismo. ¿Qué significa poseer la noción de fracción ordinaria? ¿Cuándo podemos decir que ha sido adquirida por el niño ? El educador desinformado cree en ocasiones que la adquisición se consigue cuando los alumnos son capaces de resolver los problemas que implican las nociones y las operaciones en cuestión. Ahora bien, con frecuencia, el fracaso total de la clase ante un problema planteado de una forma poco habitual revela que los niños no han asimilado la noción pertinente y simplemente utilizan un "truco".

El problema didáctico así planteado es de orden general. Refleja el hecho de que las "asignaturas" (hechos, nociones, etc.), en principio ajenas a la mente del niño, deben convertirse en elementos de su pensamiento. Sin analizar en mayor profundidad este proceso de adquisición, es preciso definir el resultado deseado, que se expresa afirmando que el niño "conoce el hecho" o que ha "adquirido la noción". Este es el primer problema importante que se plantea a cualquier especialista en didáctica. Ahora bien, compete a la psicología del pensamiento dar una respuesta con la mayor autoridad posible.

14 Pero hay más. Cualquier didáctica debe definir, y define de hecho, no solo cómo los alumnos "conocen" cierta materia, sino incluso cómo la aprenden. Tomemos el ejemplo de un pedagogo para el cual la noción de fracción es una imagen mental, depositada, como por impresión fotográfica, en la mente de los alumnos. Para poder provocar este proceso, presentará a la clase imágenes de círculos divididos en sectores, que procederá a colgar de las paredes del aula durante un largo periodo de tiempo y que hará copiar, colorear, etc. Este ejemplo ilustra una de las soluciones (por otra parte errónea, como nos encargaremos de demostrar a continuación) dadas al segundo problema didáctico que precisa una solución psicológica: el de precisar la naturaleza de los procesos de adquisición por los cuales el niño asimila los hechos y las nociones.

A la didáctica incumbe asimismo la tarea de estudiar las condiciones más favorables para estos procesos de formación. También en este caso, debemos abarcar un espectro muy amplio de problemas psicológicos, que hacen surgir los aspectos de la necesidad, del interés, de la atención o de la organización social de la actividad escolar. El maestro se apoya en su conocimiento psicológico del niño para tener en cuenta estas condiciones en su enseñanza,

El especialista en didáctica científica se fija la tarea de deducir del conocimiento psicológico de los procesos de formación intelectual las medidas metodológicas más aptas para provocarlos. Esta relación entre la didáctica y la psicología se establece pocas veces de manera consciente y directa. $\mathrm{Y}$, sin embargo, cualquier método de enseñanza es solidario de una psicología del niño y de su pensamiento, a menudo no explicitado, ciertamente, pero al que se lo presupone tácitamente. El análisis detenido de una metodología e incluso de unas simples prácticas didácticas en uso en las escuelas revela con relativa facilidad las concepciones psicológicas subyacentes.

Estas consideraciones nos han sugerido el plan siguiente para esta obra: Comenzaremos estudiando la solución dada al problema de la formación de las nociones y operaciones por la didáctica del siglo XIX. A continuación, intentaremos mostrar que esta metodología es solidaria con la psicología y la filosofía "sensualistaempírica" en boga en esa misma época. En una segunda sección de la parte histórica, repasaremos algunas teorías reformadoras del siglo XX y sus fundamentos psicológicos; en especial, varios movimientos pedagógicos agrupados habitualmente dentro del término de teorías de la "escuela activa". En un tercer apartado, consideraremos ciertos aspectos de la psicología de Jean Piaget, que nos parecen poder 
servir de base para unos principios metodológicos expuestos en capítulos siguientes. Finalmente, ilustraremos nuestras sugerencias mediante la descripción de un experimento didáctico que hemos realizado en las escuelas públicas del cantón de Zúrich.

\section{NOTAS}

1. Nota de los traductores: Para une presentación más amplia de la obra de H. Aebli en español el lector puede consultar: "El pensamiento didáctico de Hans Aebli" de Ricardo Lucio. www.pedagogica.edu.co/storage/.../rce25_05ensa.pdf

2. Nos tomamos la libertad de mostrar aquí nuestro agradecimiento a E. Kuen y E. Keller en Kusnacht y a H. Seller y T. Frey en Zúrich, que han puesto a nuestra disposición sus clases y que han hecho todo lo posible para facilitar la realización de nuestros experimentos. 